\title{
Decrease in Neuronal Uptake of Noradrenaline Simply Explains the Supersensitivity after Sympathectomy in the Rat Iris Dilator
}

\author{
Koushi SHIBATA, Satomi TAKEI, Tomoyuki KAWAI, \\ Yuji IMAIZUMI and Minoru WATANABE
}

Department of Chemical Pharmacology. Faculty of Pharmaceutical Sciences, Nagoya City University. Tanabe-Dohri 3-1. Mizuho-ku, Nagoya 467. Japan

Accepted January 19, 1989

\begin{abstract}
The effect of superior cervical ganglionectomy or long term treatment with guanethidine on the mechanical response of dilator muscle of the rat iris to several stimulants was examined. The dose-response curve for noradrenaline (NA) was significantly shifted to the left 7 days after denervation (ca. $\times 10$ ) or by treatment with guanethidine (ca. $\times 10$ ), but those for methoxamine (Meth) and acetylcholine (ACh) were not. Cocaine did not further sensitize the denervated muscle to NA, but it sensitized the normal muscle to an extent similar to that caused by denervation. Cocaine did not affect the sensitivity to Meth in both control and denervated muscles. The maximum response to NA decreased by about $30 \%$ or $20 \%$ after surgical or chemical denervation, respectively, while those to Meth. ACh and $\mathrm{Ca}^{2+}$ did not alter significantly. These results indicate that in the dilator muscle. the sympathetic denervation caused a purely specific supersensitivity to NA which was simply explained by a presynaptic mechanism: an impairment of the neuronal uptake process.
\end{abstract}

The alteration of pupil diameter after superior cervical ganglionectomy was observed in 1855 by Budge and was called "paradoxical pupilary dilation" (1). In early years of this century, the mechanism of this phenomenon was elucidated to be a supersensitivity of dilator smooth muscle to substances (adrenaline and noradrenaline) released from the adrenal medulla (2). Although the supersensitivity in smooth muscle tissues after sympathetic denervation was first found in the pupil as described above, the mechanisms of denervation supersensitivity have been extensively studied in cat nictitating membrane, rabbit arteries and rat vas deferens (3). It has been well-established that postganglionic denervation induces two distinct forms of supersensitivity, pre- and postjunctional supersensitivity (4). The prejunctional supersensitivity occurs mainly due to a loss of the neuronal uptake mechanism for catecholamines (5). while mechanisms of the postjunctional supersensitivity have not been completely elucidated.

Since the enhancement of $32 \mathrm{P}$-incorporation into phospholipids in response to noradrenaline has been shown in sympathectomized rabbit iris muscles (6), the correlation between supersensitivity and an increase in noradrenaline-induced turnover of phosphatidylinositides has been well-investigated $(7,8)$. Recently, it has been concluded that sympathectomy results in an increase in coupling between alpha ${ }_{1}$-adrenoceptor activation and the breakdown of phosphatidylinositol 4.5-bisphosphate into phosphatidylinositol trisphosphate and 1,2-diacylglycerol as a postsynaptic mechanism in rabbit iris dilator (9).

In the present study, the contribution of the presynaptic component to supersensitivity after postganglionic denervation was investigated in surgically or chemically sympathectomized rat iris dilator. As a consequence. we found that supersensitivity was fairly specific to noradrenaline and was simply 
explained by a presynaptic mechanism.

\section{Materials and Methods}

Tension measurement: Male Wistar rats denervated surgically or chemically for 2 weeks, weighing between 400 and $550 \mathrm{~g}$, or Wistar rats of both sexes denervated chemically for 10 weeks, weighing between 200 and $350 \mathrm{~g}$. were stunned by a blow on the head and killed by exsanguination. The strip preparation of the dilator muscle was made using about $1 / 6$ of the whole iris (about 3 $\mathrm{mm}$ wide measured along the outer edge of the iris) by radial cuts, using extreme care. under a binocular microscope as previously described by Narita and Watanabe (10). The dilator strip was mounted horizontally in a 3 or $4 \mathrm{ml}$ organ bath and was perfused with Krebs' solution. Resting tone was adjusted between 10 and $15 \mathrm{mg}$, which is the inherent tone of this muscle (10). Resting tone and tension changes were measured by means of isometric transducers (domestic made, see ref. 11) and recorded on a DC-recorder (Toa Electronics, Ltd., Japan). After being set up. the tissue was equilibrated for about $60 \mathrm{~min}$. During the period of equilibration, the responsiveness of the preparation to $1 \mu \mathrm{MNA}$, Meth or ACh was tested.

Transmural nerve stimulation (TNS) consisting of trains of 60 square pulses of 0.1 msec in duration was applied at $30 \mathrm{~Hz}$ in frequency through a pair of platinum electrodes set up on each side of the preparation.

Solutions: Krebs' Ringer solution of the following composition was used: $112.0 \mathrm{mM}$ $\mathrm{NaCl}, 4.7 \mathrm{mM} \mathrm{KCl}, 2.2 \mathrm{mM} \mathrm{CaCl}, 1.2 \mathrm{mM}$ $\mathrm{MgCl}_{2} .25 .0 \mathrm{mM} \mathrm{NaHCO} 3.1 .2 \mathrm{mM} \mathrm{KH}_{2} \mathrm{PO}_{4}$ and $14.0 \mathrm{mM}$ glucose. The solution in the organ bath was bubbled with a gas mixture of $\mathrm{O}_{2}(95 \%)$ and $\mathrm{CO}_{2}(5 \%)$. The temperature was maintained at about $37^{\circ} \mathrm{C}$.

Cocaine or blockers (phentolamine and atropine) were applied 15 or $10 \mathrm{~min}$ before an addition of agonists, respectively.

Experiments using $\mathrm{Ca}^{2+}$-induced contraction in depolarized or normal muscle were performed by the following method. The physiological salt solution used consisted of the following (12): $118.0 \mathrm{mM} \mathrm{NaCl}, 4.7 \mathrm{mM}$ $\mathrm{KCl}, 2.5 \mathrm{mM} \mathrm{CaCl}_{2}, 1.2 \mathrm{mM} \mathrm{MgCl}, 25.0 \mathrm{mM}$ Tris and $10.0 \mathrm{mM}$ glucose. The $\mathrm{pH}$ was adjusted with $\mathrm{HCl}$ to 7.4 and the solution was aerated with $\mathrm{O}_{2}$. Two types of $\mathrm{Ca}$-free solution were used: one was depolarizing solution containing $60 \mathrm{mM} \mathrm{KCl}$ made by replacing sodium chloride with equimolar potassium chloride (high $\mathrm{K}^{+}, \mathrm{Ca}^{2+}$-free solution) and the other was normal $\mathrm{K}^{+}, \mathrm{Ca}^{2+}$-free solution. After an equilibration period for 30 min, tissues were exposed to a high $\mathrm{K}^{+}$or normal $\mathrm{K}^{+}, \mathrm{Ca}^{2+}$-free solution containing 0.1 $\mathrm{mM}$-EGTA, $1 \mu \mathrm{M}$ phentolamine and $1 \mu \mathrm{M}$ atropine for $20 \mathrm{~min}$. The inherent tone (10-15 $\mathrm{mg}$ ) of the muscle was abolished immediately after the removal of extracellular $\mathrm{Ca}^{2+}$, and the muscle relaxed completely (13). There remained only a passive tension of less than 2 mg. which was not reduced by any relaxant such as $0.1 \mathrm{mM}$ papaverine. Thereafter, the dose-response curve for $\mathrm{Ca}^{2+}$ was obtained. $\mathrm{CaCl}_{2}$ was added without regard to the osmolarity of the solution.

Surgical denervation: Surgical denervation was performed as follows: Rats were anesthetized with an i.p. injection of a combination of thiopental sodium $(25 \mathrm{mg} / \mathrm{kg})$ and amobarbital sodium $(50 \mathrm{mg} / \mathrm{kg}$ ). The sympathetic trunk proximal to the superior cervical ganglion was cut and the ganglion was removed with short branches attached. All experiments were carried out in a paired manner using normal and denervated dilators from each animal at the same time.

Chemical denervation: Neonatal rats were denervated by daily s.c. injection of guanethidine sulfate, $50 \mathrm{mg} / \mathrm{kg}$ on days 1 to 25 and $25 \mathrm{mg} / \mathrm{kg}$ on days 26 to 90 . Denervation of adult rats was performed by daily s.c. injection of $50 \mathrm{mg} / \mathrm{kg}$ of guanethidine for 2 weeks using males, weighing between 350 and $450 \mathrm{~g}$. Control rats were injected with saline of the same volume $(10 / \mathrm{ll} / \mathrm{g} \mathrm{b}$. wt. or $2.5 \mu \mathrm{l} / \mathrm{g}$ b. wt.) according to the protocol used for the guanethidine-treated groups. The body weight of the rats treated with guanethidine from the 1st post partum day was $200-300 \mathrm{~g}$ at 10 weeks of age and slightly lower than that of the control rats. The treatment with guanethidine for 2 weeks did not significantly affect the increase in body weight: Control rats weighed $400-450 \mathrm{~g}$ and treated rats weighed $380-420 \mathrm{~g}$ at 15 weeks of age.

Catecholamine fluorescence: Freshly dis- 
sected iris was treated with glyoxilic acid to induce catecholamine fluorescence according to the method described by Furness and Costa. (14). Immediately after the rats were sacrificed, small segments of the iris were excised with a small piece of sclera along the root of the iris and placed in glyoxylic acid solution ( $2 \%$ in $0.9 \% \mathrm{NaCl}$ solution buffered to $\mathrm{pH} 7.0$ ) and incubated for $30 \mathrm{~min}$ at room temperature. They were then placed and stretched on a glass slide, air dried for about $10 \mathrm{~min}$ and heated in an oven at $100^{\circ} \mathrm{C}$ for 4 min. Specimens were mounted with Entellan-Xylene and then examined under a fluorescence microscope (Olympus model FLM).

Drug used: All drugs were dissolved in saline. When the effect of drugs was tested. the perfusion was stopped, and the bath was circulated with Krebs' solution for about $5 \mathrm{~min}$ before adding the aliquots of drug solutions $(<100 \mu l)$ to the bath. To remove the drug, the organ bath was perfused with Krebs' solution at a rate of $9 \mathrm{ml} / \mathrm{min}$.

The following drugs were used: noradrenaline bitartrate (NA) (Wako), acetylcholine chloride (ACh) (Wako), methoxamine hydrochloride (Meth) (Nihon Shinyaku), atropine sulfate (Wako), phentolamine mesylate (Regitin. Ciba-Geigy), cocaine hydrochloride (Shionogi), Tris (hydroxymethyl) aminomethane (Tris) (Wako), glycoletherdiaminetetraacetic acid (EGTA) (Wako), guanethidine sulfate (kindly supplied from Dr. Matsuki of Tokyo University and Ciba-Geigy or purchased from Tokyo Kasei).

Statistical methods: Results are expressed as mean with S.E. or $95 \%$ confidence limits. Statistical significance was tested according to Student's $t$-test or paired t-test; and $P$ levels of 0.05 and 0.01 are indicated by * and **, respectively, in the figures or tables. The slope of the dose-response curve was expressed as logit/(-log $M$ concentration). Logit (logistic function) has been defined as $\log \left[Y_{A} /\left(Y_{\max }-Y_{A}\right)\right]$, where $Y_{\max }$ and $Y_{A}$ are the maximal and submaximal responses to an agonist $(15,16)$.

\section{Results}

Confirmation of surgical and chemical denervation: The validity of the denervation procedure was confirmed in several animals by the disappearance of the noradrenergic nerves in the iris which was visualized using the glyoxylic acid technique in a whole mount preparation. The preparations from normal tissue displayed a good contrast between background (smooth muscle) and fluorescent nerve fibers, showing mesh-like greenishyellow fluorescence of intervaricose segments with strongly fluorescent varicosities. The fluorescence became weak on 1 day after the ganglionectomy, and it disappeared completely after 3 days. The disappearance was also confirmed in dilators at 4 or 7 days after ganglionectomy $(n=2$ for each). The treatment with guanethidine also completely abolished the fluorescence in both neonatal and adult rats $(n=5$ for each).

We have reported that in rat iris dilator. transmural nerve stimulation $(30 \mathrm{~Hz}, 0.1$ msec, 60 pulses) elicits a biphasic response, i.e., an initial contraction followed by a relaxation, and that the relaxing response is cholinergic, while the contractile response contains both cholinergic and adrenergic components (10). In dilator muscle denervated by superior cervical ganglionectomy or treatment with guanethidine, the atropineresistant component of contraction disappeared, indicating the abolishment of adrenergic transmission. while the response via parasympathetic nerve remained.

Influence of denervation on the contractile response of dilator to NA: Dose-response curves for NA in surgically denervated dilator were obtained at $1,3,7$ and 14 days after denervation and are shown in Fig. $1 \mathrm{~A}$ and Table 1A. The alteration in response to NA appeared as early as one day after denervation. when the dose-response curve was distinctly shifted to the left (about 3 -fold in terms of ED50, Fig. 1A, Table 1A). The extent of the maximum shift of the dose-response curve was 10-fold, and this was attained at 7 days after the operation (Table 1A). Chemical denervation also increased the sensitivity of the dilator muscle to NA (Fig. 1B, Table 1B): about 5 -fold or 9 -fold in terms of ED50 in adult or neonatal animals, respectively. Neither types of denervation altered the slope of the dose-response curves (Table $1 \mathrm{~A}$ and B). 


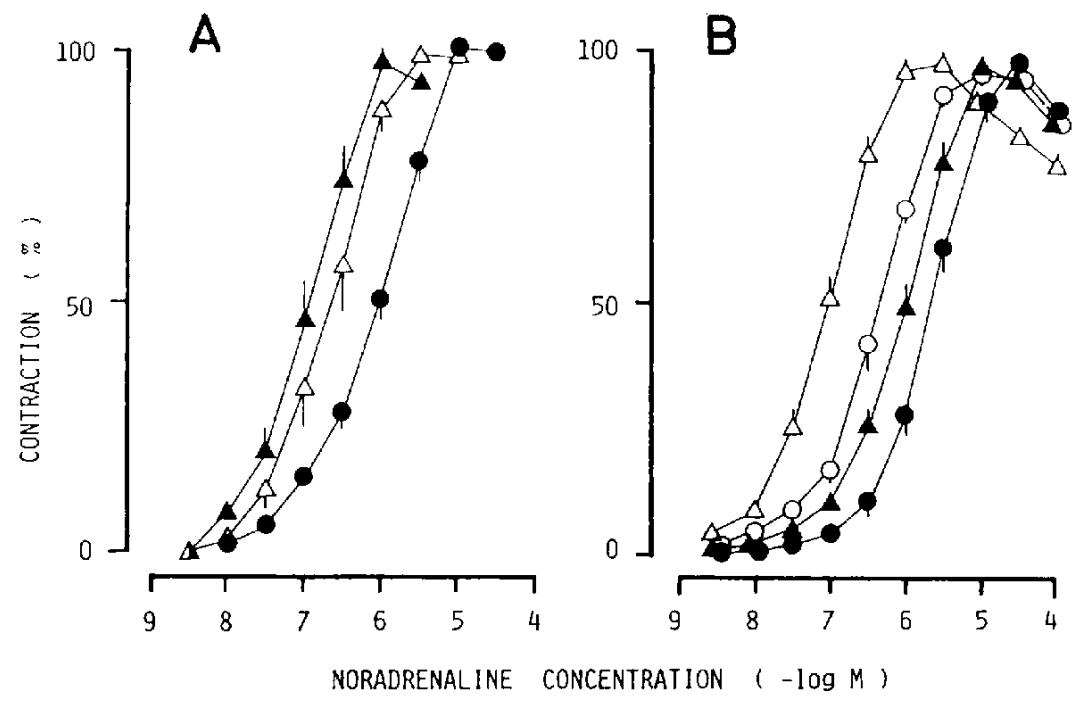

Fig. 1. Dose-response curve for NA in normal and denervated iris dilator. A: Surgical denervation. Normal (O, $n=10)$. 1 day after denervation $(\Delta, n=5), 7$ days after denervation $(\mathbf{A}, n=5)$. Contralateral innervated irides served as the control. B: Chemical denervation. Treated with saline for 2 weeks (O $\mathrm{n}=7)$ and 10 weeks $(\boldsymbol{\Delta}, \mathrm{n}=13)$. Treated with guanethidine for 2 weeks $(O, n=8)$ and 10 weeks $(\Delta, n=16)$. The irides dissected from the rats treated with saline served as the control. Maximum response to each cumulative addition of NA was taken as $100 \%$. Vertical bars represent S.E.

The maximum tension developed by NA was significantly decreased in denervated dilator (Table 1). The magnitude of maximum response is expressed as absolute developed tension ( $\mathrm{mg}$ ). since the wet tissue weight of each preparation was too light to be exactly determined ( $<1 \mathrm{mg}$ ). The decrease reached a maximum 7 days after the surgical denervation, and the final extent was about $30 \%$ of the normal response (Table 1A). The decrease in maximum response in chemically denervated muscle by 2 or 10 weeks treatment with guanethidine was about 20 and $12 \%$. respectively (Table $1 \mathrm{~B}$ )

In order to examine the possibility that the decrease in maximum response to NA was an artifact resulting from technical inaccuracy in tissue preparation, the maximum response to NA was compared with that to $\mathrm{Ca}^{2+}$. As shown previously (13). the inherent tone of this muscle depends on extracellular $\mathrm{Ca}^{2+}$ concentration, reaching a maximum at $30 \mathrm{mM}$ or more (in Tris-buffer solution, see Methods) in both normal and deneravated muscle. At first, the maximum response to NA was obtained. After recovery, the increase in tone was measured by elevating $\mathrm{Ca}^{2+}$ concen- tration from 2.5 to $32 \mathrm{mM}$ in the same preparation. The inherent tone was not affected by both surgical denervation (normal dilator: $10.75 \pm 1.79 \mathrm{mg}$; denervated: $9.59 \pm 0.97 \mathrm{mg}$, $\mathrm{N}=5$, in Krebs' solution) and chemical denervation for 2 weeks (control: 13.18 $2.01 \mathrm{mg}$; denervated: $13.20 \pm 1.65 \mathrm{mg}, n=6$, in Tris solution). There was no significant difference in the response to $32 \mathrm{mM} \mathrm{Ca}^{2+}$ between normal (11.83 $\pm 1.05 \mathrm{mg}, \mathrm{N}=5$ ) and surgically denervated muscle ( 7 days after the operation, $14.68 \pm 0.97 \mathrm{mg}, N=5, P>0.05$ ). while the maximum response to NA was significantly sma!ler in surgically denervated dilator $(6.72 \pm 0.80 \mathrm{mg} . N=5)$ than in the normal one $(10.61 \pm 0.90 \mathrm{mg}, N=5, P<0.05)$. The relative amplitude of the response to NA. taking that to high $\mathrm{Ca}^{2+}$ in each preparation as $100 \%$, was $92.2 \pm 7.9 \%(N=5, P>0.05$ vs. $100 \%)$ in normal dilator and $45.3 \pm 3.2 \%(N=5$. $\mathrm{P}<0.01$ vs. both $100 \%$ and $\mathrm{NA}$ in normal dilator) in the denervated one. The response to $32 \mathrm{mM} \mathrm{Ca}^{2+}$ was not affected by chemical denervation either (control: $17.42 \pm 2.24 \mathrm{mg}$. $n=5$; denervated: $16.35 \pm 2.08 \mathrm{mg}, \mathrm{n}=6$, $P>0.05)$.

These findings clearly indicate that sym- 
Table 1. Effects of denervation on parameters of the dose-response curve for NA

\begin{tabular}{|c|c|c|c|c|c|c|}
\hline Days & Group & $N a$ & $\begin{array}{c}\mathrm{ED} 50^{\mathrm{b}} \\
\mu \mathrm{M}\end{array}$ & $\begin{array}{l}\text { Ratio of } \\
\text { ED50'sc }\end{array}$ & $\begin{array}{l}\text { Maximum } \\
\text { response: mgd }\end{array}$ & Slopee \\
\hline \multicolumn{7}{|l|}{ A } \\
\hline \multirow[t]{3}{*}{1} & control & 10 & $\begin{array}{c}0.87 \\
(0.53-1.44)\end{array}$ & & $8.8 \pm 0.5$ & $1.00 \pm 0.05$ \\
\hline & & & & 4.36 & & \\
\hline & denervated & 10 & $\begin{array}{c}0.20 * * \\
(0.13-0.30)\end{array}$ & & $8.6 \pm 0.5$ & $1.13 \pm 0.08$ \\
\hline \multirow[t]{3}{*}{3} & control & 5 & $\begin{array}{c}0.76 \\
(0.53-1.08)\end{array}$ & & $10.9 \pm 1.6$ & $0.98 \pm 0.09$ \\
\hline & & & & 6.90 & & \\
\hline & denervated & 5 & $\begin{array}{c}0.11^{* *} \\
(0.08-0.15)\end{array}$ & & $7.7 \pm 2.2$ & $1.13 \pm 0.06$ \\
\hline \multirow[t]{3}{*}{7} & control & 10 & $\begin{array}{c}1.38 \\
(1.12-1.55)\end{array}$ & & $10.4 \pm 0.9$ & $1.04 \pm 0.06$ \\
\hline & & & & 10.5 & & \\
\hline & denervated & 10 & $\begin{array}{c}0.13^{* *} \\
(0.09-0.18)\end{array}$ & & $7.3 \pm 0.4^{*}$ & $1.18 \pm 0.04$ \\
\hline \multirow[t]{3}{*}{14} & control & 5 & $\begin{array}{c}0.71 \\
(0.51-0.98)\end{array}$ & & $11.8 \pm 1.4$ & $1.05 \pm 0.09$ \\
\hline & & & & 8.32 & & \\
\hline & denervated & 5 & $\begin{array}{c}0.09 * * \\
(0.06-0.12)\end{array}$ & & $7.8 \pm 1.1^{*}$ & $1.15 \pm 0.06$ \\
\hline \multicolumn{7}{|l|}{$B$} \\
\hline \multirow[t]{3}{*}{2 weeks } & control & 7 & $\begin{array}{l}2.09 \\
(1.75-2.51)\end{array}$ & & $12.3 \pm 0.7$ & $1.28 \pm 0.10$ \\
\hline & & & & 4.98 & & \\
\hline & denervated & 8 & $\begin{array}{c}0.42^{* *} \\
(0.35-0.51)\end{array}$ & & $9.9 \pm 0.6^{*}$ & $1.01 \pm 0.07$ \\
\hline \multirow[t]{3}{*}{10 weeks } & control & 13 & $\begin{array}{c}0.84 \\
(0.71-0.99)\end{array}$ & & $11.1 \pm 0.6$ & $1.08 \pm 0.08$ \\
\hline & & & & 9.33 & & \\
\hline & denervated & 16 & $\begin{array}{c}0.09 \cdots \\
(0.08-0.11)\end{array}$ & & $9.7 \pm 0.6$ & $1.19 \pm 0.05$ \\
\hline
\end{tabular}

A: Surgical and B: Chemical denervation. aN: number of animals: Surgically denervated and contralateral normal irides were obtained from a single animal and used in a paired manner (A). bMean of ED50 in $\mu \mathrm{M}$. In parentheses. $95 \%$ confidence limits are shown. "The ratio of ED50 of NA in denervated dilator to that in the control. "mean $\pm S . E$. expressed as logit/(- $\log M$ concentration). mean $\pm S . E$. ${ }^{*} P<0.05,{ }^{* *} P<$ 0.01 , significantly different from the control.

pathetic denervation produced an increase in sensitivity and also a decrease in maximum response to NA in iris dilator.

Absence of nonspecific component in the supersensitivity: The ED50 value, slope of dose-response curve and maximum response to Meth in denervated dilator were not significantly different from those in the normal one
(Table 2A). These parameters did not change either after chemical denervation (Table 2B).

ACh produced a relaxation at a concentration range from $1 n \mathrm{M}$ to $1 \mu \mathrm{M}$ and a contraction at concentrations higher than $1 \mu \mathrm{M}$ (Fig. 2, see also ref. 10). After surgical denervation, there was no significant change in the response to $\mathrm{ACh}$ at any dose except $0.1 \mathrm{mM}$ 
Table 2. Effects of denervation on parameters of the dose-response curve for Meth

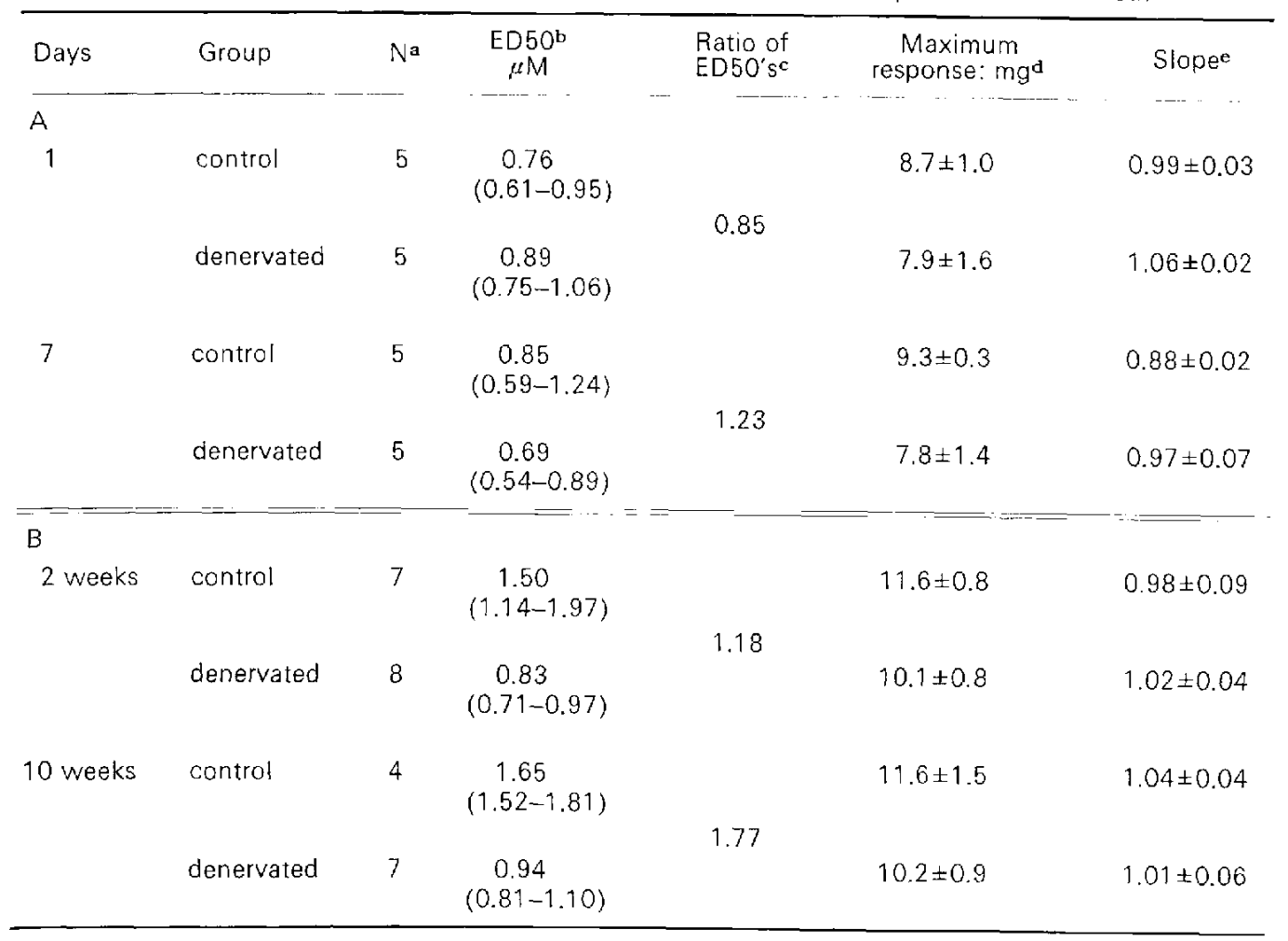

A: Surgical and B: Chemical denervation. ${ }^{2} \mathrm{~N}=$ number of animals. bMean of ED50 and its $95 \%$ confidence limits in parentheses. CThe ratio of ED50 of Meth in denervated dilator to that in the control. dmean \pm S.E. expressed as $\operatorname{logit} /(-\log M$ concentration), mean $\pm S . E$.

(Fig. 2A). Chemical denervation by the application of guanethidine for 2 and 10 weeks also did not affect the response to $\mathrm{ACh}$ at any dose (Fig. 2B).

In order to elucidate more clearly the changes in muscle contractility after denervation, the reactivity to $\mathrm{Ca}^{2+}$ was examined in normal $\mathrm{K}^{+}(5.9 \mathrm{mM})$ and high $\mathrm{K}^{+}(60 \mathrm{mM})$ solutions. As described in the prior section, the absolute values of amplitude in $\mathrm{Ca}^{2+}$. induced contractions in denervated dilator were not significantly different from those in normal ones $(P>0.05)$ at any concentrations of $\mathrm{Ca}^{2+}$, regardless of the concentration of $\mathrm{K}^{+}$ in the medium. The maximum response to $\mathrm{Ca}^{2+}$ in normal $\mathrm{K}^{+}$solution in surgically denervated muscle was not significantly different from that in the control one (control: $22.01 \pm 0.90 \mathrm{mg}$; denervated: $19.82 \pm$ $1.27 \mathrm{mg} . \mathrm{N}=5$ for each). This was also the case for chemically denervated muscle (con- trol: $17.42 \pm 2.24 \mathrm{mg}$; denervated: $16.35 \pm$ $2.08 \mathrm{mg}$. $\mathrm{n}=6$ for each). The maximum response to $\mathrm{Ca}^{2+}$ in high $\mathrm{K}^{+}$solution was affected by neither surgical (control: $11.83 \pm$ $1.05 \mathrm{mg}$; denervated: $14.51 \pm 1.01 \mathrm{mg}, \mathrm{P}>$ $0.05, N=5$ for each) nor chemical denervation (control: $16.03 \pm 1.85 \mathrm{mg}$; denervated: $15.48 \pm$ $1.59 \mathrm{mg}, P>0.05, n=6$ for each). The sensitivity to $\mathrm{Ca}^{2+}$ was also unaffected by both surgical and chemical denervation (Fig. 3).

Mechanism of specific supersensitivity: Cocaine $(30 \mu \mathrm{M})$ sensitized the innervated muscle to NA to an extent similar to those seen after surgical denervation per se (Fig. 4), while cocaine did not produce further sensitization in the surgically denervated muscle. Sensitivity to Meth was not affected by the application of $30 \mu \mathrm{M}$ cocaine in both control and surgically denervated muscle (Fig. 4). When the maximum response to NA in the absence of cocaine was taken as $100 \%$. 


\section{ACETYLCHOLINE CONCENTRATION $(-\log M)$}
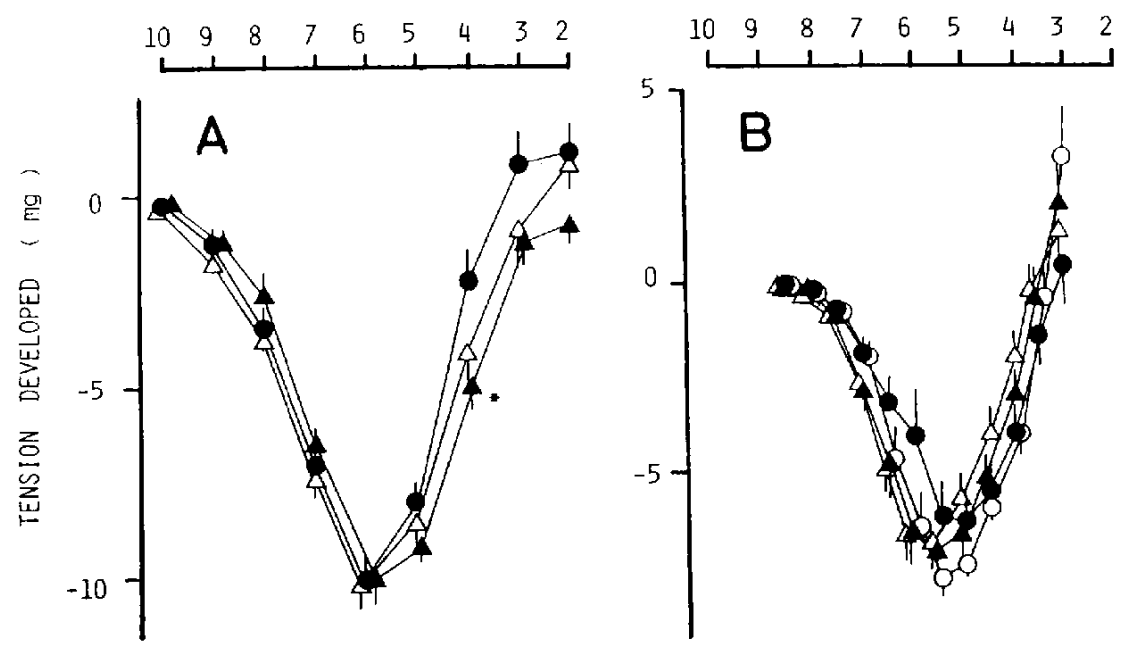

Fig. 2. Dose-response curves for ACh in normal and denervated iris dilator. Ordinate: value of tension in $\mathrm{mg}$. The level of inherent tone is expressed as $0 \mathrm{mg}$. A: Surgical denervation. Normal $(\mathbf{O}, \mathrm{n}=10)$, 1 day after denervation $(\triangle, n=5), 7$ days after denervation $(\Lambda, n=5)$. B: Chemical denervation. Treated with saline for 2 weeks $(\boldsymbol{O}, n=9)$ and 10 weeks $(\boldsymbol{\Lambda}, n=9)$. Treated with guanethidine for 2 weeks $(0$. $n=8)$ and 10 weeks $(\triangle, n=10)$. Vertical bars represent $S$.E. ${ }^{*} P<0.05$ significantly different from the control.

the relative responses to $\mathrm{NA}$ in the presence of $30 \mu \mathrm{M}$ cocaine were $96.6 \pm 4.58 \%(n=5$. $P>0.05$ vs. $100 \%)$ and $108.5 \pm 3.79 \%(n=5$. $\mathrm{P}>0.05$ vs. both $100 \%$ and $96.6 \%$ ) in normal and surgically denervated dilator, respectively.

In chemically denervated muscle, $10 \mu \mathrm{M}$ cocaine did not produce further sensitization to NA. The - log ED50 values in the muscle treated with guanethidine for 2 weeks was as follows: control: $5.68 \pm 0.08$ and $6.68 \pm 0.19$ : denervated: $6.37 \pm 0.08$ and $6.80 \pm 0.15$, in the absence or presence of $10 \mu \mathrm{M}$ cocaine, respectively. The values in chemicaily treated muscle for 10 weeks from birth were as follows: control: $6.08 \pm 0.07$ and $6.76 \pm 0.06$; denervated: $7.05 \pm 0.08$ and $6.81 \pm 0.11$, in the absence or presence of $10 \mu \mathrm{M}$ cocaine, respectively. The application of cocaine (10 $\mu \mathrm{M})$ did not affect the maximum response to NA and the sensitivity to Meth in both control and chemically denervated muscle.

Therefore, cocaine little affected the maximum response to NA in both normal and surgically or chemically denervated muscle.

\section{Discussion}

Both surgical and chemical sympathectomy of the iris induced a marked increase in sensitivity of this tissue to NA, but caused little or no change in the sensitivity to $\mathrm{ACh}$. Meth and $\mathrm{Ca}^{2+}$. It can be concluded that the supersensitivity is purely specific to NA. One of the mechanisms often proposed to explain specific supersensitivity is a change in either affinity or density of alpha-adrenoceptors (3). This possibility, however, can be ruled out since sensitivity to methoxamine was not altered by denervation. Thus a very likely possible mechanism for this specific supersensitivity is that there is a decrease in inactivating function via uptake and/or metabolic degradation of NA. Trendelenburg et al. (5) have pointed out that the magnitude of the rapidly developing supersensitivity to sympathomimetics in nictitating membrane after a surgical denervation is proportional to the relative rates of decrease in neuronal uptake. In the present results, abolishment of the NA uptake mechanism after degeneration of adrenergic nerve endings accounts for most of the demonstrated enhanced sensitivity to NA, because cocaine, an uptake-inhibitor (17), sensitized the normal muscle to an extent similar to that observed after denerva- 

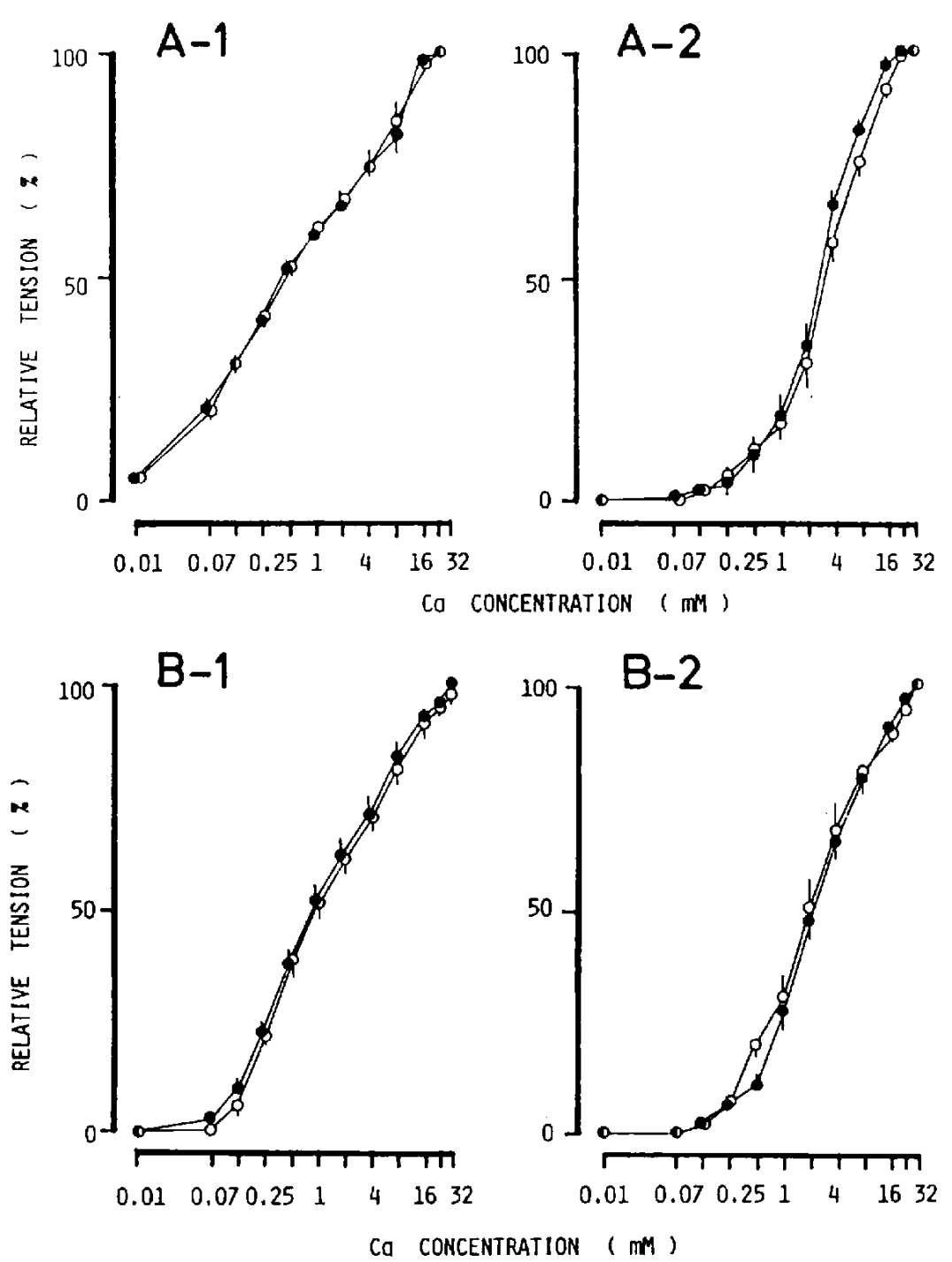

Fig. 3. Effect of denervation on the Ca-induced contraction in normal $K^{+}$solution $(A-1$ and $B-1)$ and $60 \mathrm{mM} \mathrm{K}+$ solution (A-2 and B-2). Response was expressed as \% of each maximum response. A: Surgical denervation. : control $(n=5), O: 7$ days after denervation $(n=5)$. B: Chemical denervation for 2 weeks.

: control $(n=6) . O$ : denervated $(n=6)$. Experiments were performed in the presence of $1 \mu \mathrm{M}$ phentolamine and $1 \mu \mathrm{M}$ atropine. Vertical bars represent S.E.

tion. Cocaine did not further potentiate the response to NA in surgically denervated dilator. The muscle treated with guanethidine for 2 weeks was still sensitized slightly by cocaine $(10 \mu \mathrm{M})$. On the other hand, further sensitization was no longer observed in the dilator isolated from rats treated for 10 weeks from their birth. The most important finding is that the maximum shift of ED50 for NA was approximately 10 times in any procedure for sensitization. i.e., surgical or chemical denervation, the application of cocaine or combination of them. Therefore, it seems that 2 weeks treatment was not enough to abolish the neuronal NA uptake, although the fluorescence of NA in the dilator almost disappeared. These results may indicate, conversely, that the concentration of cocaine used in this study 


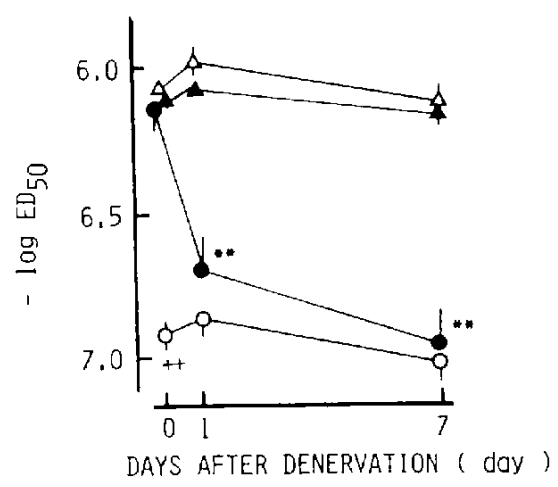

Fig. 4. Effects of $30 \mu \mathrm{M}$ cocaine on the sensitivity to NA and Meth in normal or denervated rat iris dilator. and $O$ Responses to $N A$ in the absence and presence of cocaine, respectively. $\boldsymbol{\Delta}$ and $\Delta$ : Responses to Meth in the absence and presence of cocaine, respectively. Vertical bars represent S.E. Each point for normal tissue represents the mean of ten observations, and each point for denervated tissue represents the mean of five observations. ${ }^{*} \mathrm{P}<0.01$ vs. $O$ day (normal tissue), ${ }^{++}: P<0.01$ vs. Response to NA of normal tissue in the absence of cocaine.

(30 $\mu \mathrm{M}$ or $10 \mu \mathrm{M}$ ) completely inhibits the neuronal uptake system for noradrenaline. The finding that the sensitivity to methoxamine. which is not available for neuronal uptake (5), was affected by neither surgical nor chemical denervation provides additional evidence to support our above-described assumption.

Although the correlation between sympathetic denervation and turnover of phosphatidylinositides has been studied in several tissues (18), consistent results have not been observed. In rabbit iris dilator, the data obtained by Abdel-Latif and his collegues (7-9) strongly suggested that supersensitivity after superior cervical ganglionectomy is due to the enhancement of NA-induced breakdown of phosphatidylinositol 4,5bisphosphate into myo-inositol trisphosphate and 1.2-diacylglycerol. The results obtained in the present study clearly shown that this is not the case in rat iris dilator. The supersensitivity is quite specific to NA and not to other drugs including Meth and can be simply explained by the impairment of neurona! NA uptake.

It is of interest that after superior cervical ganglionectomy, a specific supersensitivity occurs in the middle cerebral artery of the cat (19) and iris dilator of the rat (present study). while nonspecific or, in other words. postsynaptic supersensitivity occurs in the nictitating membrane of the cat (20) and ear artery of the rabbit (21). Contrary to these observations is the finding that in the middle cerebral artery of the cat and rabbit, there is no significant alteration of reactivity to drugs after denervation (21). Additionally, it is a very common observation that adrenergic postganglionic denervation produces nonspecific supersensitivity in a target smooth muscle tissue, especially in densely innervated tissues having a close contact between smooth muscle cells and nerve endings (2). In the rat vas deferens, the nonspecific component of supersensitivity develops very quickly and reaches a maximum 4 days after denervation (22). In this respect, the present result in rat iris dilator is rather unusual. Another occurrence of specific supersensitivity after surgical sympathectomy has been reported in rat portal vein (23). It is clear that the present study presents one of the most typical examples of purely specific supersensitivity ever found.

An unexpected result obtained in the present study is that signifcant decrease in maximum response to NA after denervation. It is very unlikely that the decrease in maximum response to NA is an artifact because of the following reasons: 1) The maximum responses to $\mathrm{Ca}^{2+}$ was not affected by denervation. 2) The decrease was observed in both surgically or chemically denervated muscle. The former observation suggests that denervation did not cause a significant degeneration of the dilator muscle itself. It has been, however, reported that a decrease in maximum response to NA occurs in rabbit ear artery after long term denervation to a similar extent as shown here (24). The decrease in maximum response has been found together with a decrease in wall thickness of the vessel. In the present study, wet or dry tissue weight of each dilator segment preparation could not be determined. Therefore, the possibility that degeneration of dilator muscle occurred after denervation can not be ruled out completely. Another mechanism has been 
suggested in denervation-induced decrease in maximum response to Meth in chick expansor secundariorum muscle (25). The decrease in number of alpha-1-adrenoceptors may contribute to the decrease in maximum response in that preparation. It is not really clear whether this mechanism is also the case in the present study, because the decrease in maximum response to Meth after denervation was not statistically significant, but there was a tendency of a decrease. Although the mechanism of the decrease in maximum response to NA after denervation could not be fully clarified, it is apparently due to postsynaptic change. A combination of the mechanisms discussed above might make the problem more complicated.

In conclusion, supersensitivity induced by surgical and chemical sympathectomy in rat iris dilator has an almost pure presynaptic nature and can be simply explained by an impairment of neuronal NA uptake. The concomitant decrease in the maximum response to $\mathrm{NA}$ is due to postsynaptic mechanisms that remain to be clarified.

\section{References}

1 Langendorff, O.: Die Deutung der "paradoxen" Pupillenerweiterung. Klin. Mbl. Augenheilk. 38, 823-827 (1900)

2 Fleming, W.W., McPhillips, J.J. and Westfall, D.P.: Postjunctional supersensitivity and subsensitivity of excitable tissues to drugs. Reviews of Physiology 68, 55-119 (1973)

3 Westfall, D.P.: Supersensitivity of smooth muscle. In Smooth Muscle. Edited by Bülbring. E., Brading, A.F., Jones, A.W. and Tomita, T., p. 285-309. Edward Arnold. Ltd.. London (1981)

4 Fleming, W.W.: Supersensitivity in smooth muscle: introduction and historical perspective. Fed. Proc. 34, 1969-1970 (1975)

5 Trendelenburg, U., Maxwell, R.A. and Pluchino, S.: Methoxamine as a tool to assess the importance of intraneuronal uptake of I-norepinephrine in the cat's nictitating membrane. J. Pharmacol. Exp. Ther. 172, 91-99 (1970)

6 Abdel-Latif, A.A., Green, K., Matheny, J.L., McPherson, J.C. and Smith, J.P.: Effects of norepinephrine and acetylcholime on ${ }^{32} \mathrm{P}$ incorporation into phospholipids of the rabbit iris muscle following unilateral superior cervical ganglionectomy. Life Sci. 17. 1821-1828 (1975)

7 Abdel-Latif, A.A., Green, K., Smith, J.P., Mc-
Pherson, J.C. and Matheney, J.L.: Norepinephrine-stimulated breakdown of triphosphoinositide of rabbit iris smooth muscle: effects of surgical sympathetic denervation and in vivo electrical stimulation of the sympathetic nerve of the eye. J. Neurochem. 30, 517-525 (1978)

8 Abdel-Latif, A.A., Green, K. and Smith, J.P.: Sympathetic denervation and the triphosphoinositide effect in the iris smooth muscle: a biological method for the determination of $\alpha$ adrenergic receptor denervation supersensitivity. J. Neurochem. 32, 225-228

9 Akhtar, R.A. and Abdel-Latif, A.A.: Surgical sympathetic denervation increases $\alpha_{1}$-adrenoceptor-mediated accumulation of myoinositol trisphosphate and muscle contraction in rabbit iris dilator smooth muscle. J. Neurochem. 46, 96-104 (1986)

10 Narita, S. and Watanabe, M.: Response of isolated rat iris dilator to adrenergic and cholinergic agents and electrical stimulation. Life Sci. 30. 1211-1218 (1982)

11 Narita, S. and Watanabe, M.: Response of the isolated rat iris sphincter to cholinergic agents and electrical stimulation. Life Sci. 29, 285-292 (1981)

12 Karaki, H., Suzuki, T. and Urakawa, N.: Tris does not inhibit isolated vascular or intestinal smooth muscle contraction. Am. J. Physiol. 214, H37H41 (1981)

13 Narita, S. and Watanabe, M.: Effects of calcium blockers and $\mathrm{Mn}^{2+}$ on the response of isolated rat iris sphincter and dilator muscles to agonists and $\mathrm{Ca}^{2+}$. J. Pharmacobiodyn. 5, 285-294 (1982)

14 Furness, J.B. and Costa, M.: The use of glyoxylic acid for the fluorescence histochemical demonstration of peripheral stores of noradrenaline and 5 -hydroxytryptamine in whole mounts. Histochemistry 41, 335-352 (1975)

15 Berkson, J.: Application of the logistic function to bio-assay. J. Am. Stat. Assoc. 39, 357-365 (1944)

16 Gaddum, J.H.: Bioassays and mathematics. Pharmacol. Rev. 5, 87-134 (1953)

17 Trendelenburg, U.: Supersensitivity by cocaine to dextrorotatory isomers of norepinephrine and epinephrine. J. Pharmacol. Exp. Ther. 148, 329338 (1965)

18 Takenawa, T., Masaki, T. and Goto, K.: Increase in norepinephrine-induced formation of phosphatidic acid in rat vas deferens after denervation. J. Biochem. 92, 303-306 (1983)

19 Edvinsson, L., Aubineau, P., Owman, C., Sercombe, R. and Seylaz, J.: Sympathetic innervation of cerebral arteries: Prejunctional 
supersensitivity to norepinephrine after sympathectomy or cocaine treatment. Stroke 6, 525530 (1975)

20 Morrison, J.M. and Fleming, W.W.: Supersensitivity of decentralized and denervated nictitating membrane to barium. Proc. Soc. Exp. Biol. 136, 196-199 (1971)

21 Araki, H., Su, C. and Lee, J.F.: Effect of superior cervical ganglionectomy on the sensitivity of rabbit ear artery and cerebral arteries of rabbit and cat to vasoactive agents. J. Pharmacol. Exp. Ther. 220, 49-55 (1982)

22 Kasuya, Y., Goto, K., Hashimoto, H., Watanabe, H., Muranaka, H. and Watanabe, M.: Nonspecific denervation supersensitivity in the rat vas deferens 'in vitro'. Eur. J. Pharmacol. 8, 177-184
(1969)

23 Johansson, B., Ljung, B., Malmfors, T. and Olson, L.: Prejunctional supersensitivity in the rat portal vein as related to its pattern of innervation. Acta Physiol. Scand. [Supp.] 349, 5-16 (1970)

24 Bevan, R.D. and Tsuru, H.: Long-term denervation of vascular smooth muscle causes not only functional but structural change. Blood Vessels 16, 109-112 (1979)

25 Williams, K., Bennett, T. and Strange, P.G.: Effects of noradrenergic denervation on alpha-1 adrenoceptors and receptor-stimulated contraction of chick expansor secundariorum muscle. J. Pharmacol. Exp. Ther. 241, 939-949 (1987) 